\title{
Weltpremiere des World Doctors Orchestra: eine Vision wurde Wirklichkeit
}

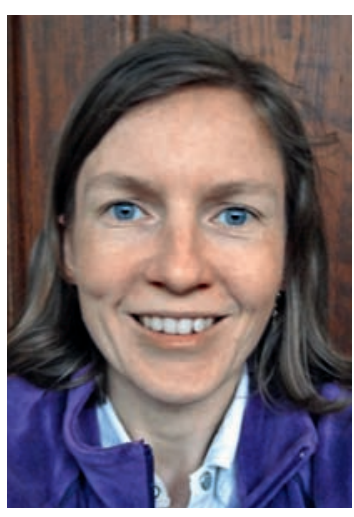

Sandra Krüger

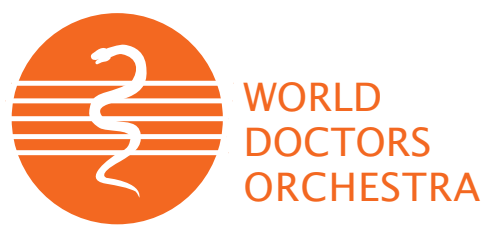

Die Idee des ersten Welt-Ärzte-Orchesters entstand schon vor einiger Zeit. Seit 2007 arbeiteten Prof. Stefan Willich, Leiter des Instituts für Sozialmedizin der Charité - Universitätsmedizin Berlin, und engagierte Kollegen ernsthaft an deren Umsetzung. Es wurden Annoncen in Ärztezeitungen rund um den Globus geschaltet und eine Internetseite aufgebaut, die Neuigkeiten, Wissenswertes und Hintergrundinformationen zu diesem Orchester vermittelt.

Als ich von diesem Orchester erfahren habe, war ich sofort von der Idee begeistert und schickte meine Bewerbung. Zwei Monate vor der ersten Probe erhielt ich das Notenmaterial und war glücklich, zu den Auserwählten zu gehören. Jetzt hiess es üben, üben, üben, denn auf dem

\section{Ärzte treten für die Idee einer medizinischen Versorgung aller Menschen unabhängig von wirtschaftlichen und politischen Interessen und nationalen Grenzen ein}

\footnotetext{
* Dr. med. Sandra Krüger, Sportmedizinerin, in Weiterbildung zur Fachärztin für Orthopädie, ist regelmässige redaktionelle Mitarbeiterin der SÄZ und als Violinistin Mitglied des World Doctors Orchestra.
}

kümmert sich um HIV-Infizierte und betreibt Tuberkulosevorsorge. Der aus Boston stammende Violinist Peter Zazofsky, der 1983 bereits mit den Berliner Philharmonikern brillierte, unterstützt das World Doctors Orchestra als Solist.

Achtzig Ärzte aus zwanzig Nationen wurden eingeladen. Am 1. Mai trafen wir alle zur ersten gemeinsamen Probe zusammen, aufgeregt, neugierig und ganz gespannt auf dieses grossartige Projekt. Auch unser Dirigent war ziemlich nervös: Würden alle kommen, gut vorbereitet sein würde das Projekt gelingen? Nachdem wir dann ohne grössere Probleme den Dvořák das erste Mal gemeinsam gespielt hatten, legte sich die Nervosität, und auch Prof. Willich war deutlich erleichtert. Feinheiten übten wir am Nachmittag in den Registerproben, die durch professionelle Musiker geleitet wurden - ihnen sei an dieser Stelle nochmals herzlich gedankt.

In einem ersten Orchestermeeting am 2. Mai haben wir über unsere Zukunft nachgedacht. Dabei wurde klar: Die Stimmung ist gut, uns eint die Freude an der Musik, es ist interessant, Kollegen aus aller Welt kennenzulernen. Doch geht es uns nicht um den künstlerischen Selbstzweck. Ziel ist, ein Zeichen zu setzen, sich ideell und finanziell dafür einzusetzen, eine von nationalen Grenzen und politischen oder wirtschaftlichen Interessen unabhängige medizinische Versorgung der gesamten Weltbevölkerung zu realisieren. Deshalb koppelt das World Doctors Orchestra mit seinen Benefizkonzerten das Nützliche an das Angenehme. So soll in einer breiten Öffentlichkeit das Bewusstsein für die Notwendigkeit eines globalen sozialen Selbstverständnisses geschärft werden: Medizinische Versorgung ist ein Menschenrecht und Voraussetzung aller menschlichen Entwicklung.

Nach drei langen Probetagen fand am Nachmittag des 3. Mai im Sinne einer Generalprobe ein Patientenkonzert in der Berliner Charité statt. Am 4. Mai 2008 um 20 Uhr war es schliesslich soweit: Das World Doctors Orchestra feierte im Kammermusiksaal der Berliner Philharmonie seine Weltpremiere. Die Begeisterung war gross unser Traum ist wahr geworden. So blicken wir hoffnungsvoll in die Zukunft. Für 2009 sind weitere Benefizkonzerte, auch ausserhalb Europas, geplant. Das World Doctors Orchestra soll damit weiterhin eine Vision zum Klingen bringen.

Sandra Krüger* 